\title{
O FENÔMENO DO RETORNO DA RELIGIÃO E SECULARIZAÇÃO SEGUNDO GIANNI VATTIMO
}

\author{
Antonio Glaudenir Brasil Maia ${ }^{1}$
}

\begin{abstract}
Resumo: O trabalho propõe realizar uma análise do retorno do fenômeno da religião no âmbito da experiência pós-moderna, com atenção particular as reflexões de Gianni Vattimo. Nessa orientação, Vattimo conduz o discurso sobre o fenômeno do retorno da religião ao âmbito da Filosofia tematizando a dissolução das principais teorias filosóficas que julgavam ter liquidado a religião. Ao invés de se pensar na supressão da religião, pretende-se investigar as possibilidades do discurso religioso. $\mathrm{O}$ fenômeno do religioso é (re)interpretado por Vattimo, em particular, por sua dimensão secularizante que ousadamente 'aproxima' do niilismo, transformando o pensiero debole na metáfora da secularização nos tempos atuais.
\end{abstract}

Palavras-chaves: Filosofia, Secularização, Religião.

Abstract: The paper proposes to perform an analysis of the return of the phenomenon of religion in post-modern experience, with particular attention the reflections of Gianni Vattimo. In this orientation, Vattimo leads the discussion on the phenomenon of the return of religion to the scope of philosophy thematising the dissolution of the main philosophical theories that thought they had settled the religion. Instead of thinking in the suppression of religion, we intend to investigate the possibilities of religious discourse. The phenomenon of religion is (re) interpreted by Vattimo, in particular, for its secularizing dimension that boldly 'approaches' nihilism, turning the pensiero debole in the metaphor of secularization in current times.

Keywords: Philosophy, Secularization, Religion.

De maneira geral, a filosofia de Vattimo tem como questão central a crítica à metafísica e a problemática da religião que a acompanha parte, de certa forma, de um interesse vivencial, de sua experiência existencial antes mesmo que por razões teóricas. É fundamental o reforço da assertiva de que na experiência existencial ocorre um reencontro, uma retomada daquilo que, para muitos, parecia ter sido 'abandonado'. É claro que, com os desdobramentos de sua reflexão filosófica, o interesse pela questão do

\footnotetext{
${ }^{1}$ Doutor em Filosofia. Professor do Curso de Filosofia da Universidade Estadual Vale do Acaraú [UVA] e do Mestrado em Filosofia da Universidade Estadual do Ceará [UECE]. Coordenador do Grupo de Pesquisa Filosofia da Religião [Gephir/CNPq]. Atualmente desenvolve estágio pós-doutoral na Universidade Federal do Ceará [UFC/CAPES]. E-mail: glaudenir@gmail.com.
} 
religioso não se resume a sua condição pessoal, ou melhor,

[...] traços do retorno da herança, que poderiam parecer ligados a sua vida pessoal (de início, católico muito empenhado, em seguida, distanciando-se do credo cristão e, atualmente, através de sua experiência de filósofo na época pós-moderna e da época pós-moderna retorna a fé cristã por meio da reflexão teórica e pessoal), são, para Vattimo, não elementos extrínsecos e privados, mas constitutivos da experiência religiosa de nossa época. (MONACO, 2006, p. 57-58.)

Em seu texto $O$ vestígio do vestígio, exposto no seminário de Capri, por volta de 1994, desenvolve a hipótese do retorno do sagrado em nossa época não ser um fato puramente acidental. Ele diz que, ao contrário, o reaparecimento é um aspecto essencial da experiência religiosa, da religião experimentada como um retorno.

Diz amiúde que experiência religiosa é a experiência de um êxodo; mas se êxodo for, trata-se provavelmente da partida para uma viagem de retorno. Talvez não devido a uma natureza essencial qualquer; mas, de fato, em nossas condições de existência (Ocidente cristão, modernidade secularizada, estado de ânimo de final de século tenso devido aos prementes e inéditos riscos apocalíticos), a religião é experimentada como um retorno. É o restabelecimento presente de algo que acreditávamos ter esquecido definitivamente, a reativação de um vestígio adormecido, a reabertura de uma ferida, a reaparição de algo que fora removido, a revelação de que o que pensávamos ter sido uma Überwindung (superação, aquisição de veracidade e consequente descarte) ainda é somente uma Verwindung, uma longa convalescença que tem de tornar a enfrentar o vestígio indelével de sua doença (VATTIMO; DERRIDA, 2000, p. 91).

A análise do fenômeno do retorno do interesse pelo religioso pode ser compreendida, a nosso ver, pelo menos sob duas tipologias de motivações, a saber: de um lado, o renovado interesse na 'cultura comum' e, do outro, no pensamento crítico ou filosófico. $\mathrm{Na}$ cultura comum se verifica o ressurgimento do interesse do religioso motivado pelos riscos globais inéditos na história da humanidade, entre alguns exemplos, a guerra nuclear, as ameaças ecológicas, a manipulação genética. Também o medo da perda do sentido da existência, acompanhado do tédio ligado ao consumismo, um retorno que tem como principal justificativa fundamentalmente a "[...] recusa da modernização enquanto causa de uma destruição das raízes autênticas da existência" (VATTIMO; DERRIDA, 2000, p. 93). Em consequência disso, a retomada da figura do Deus metafísico como fundamento último é nostalgicamente evocado para a defesa do humano. Este aspecto constitui um dos problemas centrais para a tarefa da Filosofia ante o renovado interesse pela religião.

Vattimo, na obra Acreditar em acreditar, reconhece ainda que "[...] o retorno da religião e do problema da fé não se pode colocar independentemente da história mundana [...]” (VATTIMO, 1998, p. 12), e declara que está

[...] convencido, como dizia Girard, que hoje se retorna a religião por que se

\begin{tabular}{|c|c|c|c|c|}
\hline Revista Qialectus & Ano 2 & n. 4 & Janeiro-Junho 2014 & p. $150-158$ \\
\hline
\end{tabular}


compreendeu que todos os saberes, que se consideravam definitivos, descobriram ser dependentes de paradigmas históricos, de condicionamentos de natureza diversa: social, político, ideológico e assim vai. (VATTIMO; GIRARD, 2006b, p. 20).

Não obstante ao cenário da renovada atualidade da religião na cultura comum, Vattimo ressalta que o ressurgimento do interesse pelo religioso não se limita a explicações externas. Do ponto de vista do pensamento crítico/filosófico, ao contrário, o retorno vem pensado distante de cada pretensão fundacionalista e, sobretudo, leva em consideração o plano das transformações no mundo do pensamento, das teorias muito distantes da postura que concebe a religião apenas como reação aos efeitos da sociedade de massa. Nessa orientação, Vattimo conduz o discurso sobre o fenômeno do retorno da religião ao âmbito da Filosofia com base na sentença de que

A verdade é que o 'fim da modernidade', ou, em todo o caso, a sua crise,
trouxe também consigo a dissolução das principais teorias filosóficas que
julgavam ter liquidado a religião: o cientismo positivista, o historicismo
hegeliano e depois o marxismo. Hoje já não existem razões filosóficas
plausíveis e fortes para ser-se ateu ou para recusar a religião (VATTIMO,
1998, p. 17).

A recusa de qualquer autoridade transcendente, seja pela via aberta pela ciência experimental da natureza, seja pela via da fé no desenvolver progressivo da emancipação do homem na história, representam o esforço do racionalismo [ateísta], que na Modernidade assume tais vias. Vattimo diz que esses tipos de racionalismos convergem na concepção da religião como erro, a ser desmentido pela racionalidade cientifica, tal como presumia a concepção positivista do progresso. Como se sabe, ao longo da história do pensamento ocidental, as chamadas metafísicas totalizantes construíram os chamados 'absolutos terrestres', configurados como a negação do chamado 'absoluto divino', até certo ponto, pretenderam - e ainda pretendem - cancelar o espaço da fé. Dentre eles, podem ser citados, segundo interpreta Vattimo, o positivismo (que considerava a fé como ilusão), o hegelianismo (para o qual a religião nada mais é senão um avistamento mítico de alguma verdade a ser desvelada em sua plenitude pela razão filosófica), o materialismo dialética (a fé como alienação).

A filosofia contemporânea, em alguns pontos mais avançados e conscientes [...], construíram os instrumentos conceituais mais eficazes para a demolição destes 'absolutos terrestres'. E, assim feito o trabalho de demolição, é necessário e hoje sempre mais urgente: a fé, de fato, não e possível em um universo no qual o homem fosse apenas corpo; em um universo no qual a linguagem científica fosse a única linguagem dotada de sentido; no qual, o sentido da vida do indivíduo e da humanidade, na sua completude, fosse determinada pelas inelutáveis leis de desenvolvimento da história; no qual, a totalidade da realidade se resolvesse apenas no universo físico. Por isso: para quê a mensagem religiosa tenha o espaço de escuta é necessário que antes

\begin{tabular}{|l|l|l|l|l|}
\hline Qepista 2 ialectus & Ano 2 & n. 4 & Janeiro-Junho 2014 & p. 150-158 \\
\hline
\end{tabular}


sejam destruídos os 'absolutos terrestres'. (ANTISERI; VATTIMO, 2008, p. 20)

Os interditos, pronunciados pela Filosofia contra a religião, cessam justamente com base na dissolução dos grandes sistemas. A revitalização da religião coincide com o abandono da noção de fundamento e da perda da capacidade de atribuir total sentido à existência por parte da Filosofia e do pensamento crítico em geral, isto é, a religião se torna o refúgio para tal busca de sentido e de 'fundamentação'. Esse abandono, no entanto, pode significar um retorno do Deus metafísico, fundamento imóvel da história, projeção dos temores humanos, expresso na necessidade do retorno da religião na consciência comum. Nesse sentido, não será difícil encontrar uma evidente 'aporia' entre o pensamento comum e o pensamento crítico.

Vattimo entende que o fim dos grandes sistemas [o fim da metafísica] impõe uma precisa missão a reflexão crítica, que busca se apresentar como interpretação autêntica da necessidade religiosa da consciência comum. A missão consiste, então, em demonstrar que a necessidade da consciência comum não seja satisfeita adequadamente com a pura e simples retomada da religiosidade 'metafísica', do renovado fundacionalismo ante a modernização da sociedade secularizada. A tarefa da crítica é, dada a plausibilidade da religião descoberta pela Filosofia em meio à dissolução dos metarelatos metafísicos e para além dos esquemas da crítica iluminista, possibilitar que o reencontro da religião seja compreendido nas condições históricas da existência na modernidade tardia, não a uma retomada dos dogmas e princípios metafísicos. Isso ocorre em virtude da tendência que radicaliza criticamente a consciência comum e toda e qualquer pretensão, seja de uma recaída em um Deus como fundamento, seja em função de retomada da Metafísica. De fato, a reação da consciência comum é, em sua totalidade, 'inadequada' a leitura do acontecer do fim e do ultrapassamento da metafísica.

Vale apenas lembrar que para a sua leitura do retorno da religião Vattimo se apropria se apropria do anúncio nietszscheano da 'morte de Deus' e do fim da Metafísica em Heidegger, e assim se expressa:

[...] em primeiro lugar, tentei mostrar como o fim da metafísica, vista como crença em uma ordem fundada, estável, necessária e objetivamente cognitiva do ser, foi acompanhada, no pensamento e na prática social, pela morte do Deus moral, do Deus dos filósofos, mas, também, por um renascimento do sacro em muitíssimas formas. Em seguida, insisti quanto ao fato de que, no autor que mais coerentemente afirmou o fim e a superação da metafísica, ou seja, em Heidegger, este fim significa a passagem de uma concepção do ser como estrutura para uma concepção do ser como evento, caracterizada por uma tendência ao enfraquecimento. (VATTIMO, 2004, p. 33).

\begin{tabular}{|l|l|l|l|l|}
\hline Qevista Dialectus & Ano 2 & n. 4 & Janeiro-Junho 2014 & p. 150-158 \\
\hline
\end{tabular}


Desse modo, o anúncio nietzscheano da 'morte de Deus' associado magistralmente ao fim da Metafísica, sentenciado por Heidegger, são reconhecidos como eventos que, liberando a validade do simbólico, liberam também a possibilidade do simbólico religioso, inferindo assim o 'parentesco' entre a mensagem bíblica da história da salvação e o enfraquecimento que a Filosofia descobre como traço característico da história do ser. Para ele, este parentesco se chama "secularização, entendida em sentido mais amplo, que abarca todas as formas de dissolução do sacro, características do enfraquecimento do ser, isto é, a kénosis de Deus, que é o núcleo da história da salvação”.

As possibilidades teóricas que se abrem como fruto da 'secularização como retomada, prossecução, interpretação dos conteúdos da revelação cristã', permitem a Vattimo aproximar a sua ontologia niilista e a kénosis de Deus para reinterpretar o cristianismo em nossa cultura, concebendo a hermenêutica como herdeira do mito cristão da encarnação de Deus, como filosofia não-metafísica de caráter essencialmente interpretativo da verdade.

Além da influência de Nietzsche e Heidegger, Vattimo declara que René Girard influenciou o seu re-encontro (niilista) com o cristianismo. Segundo sustenta Vattimo:

[...] a leitura de Girard foi tão decisiva quanto foi a de alguns textos de Heidegger que, em uma época diversa da minha vida, marcara-me profundamente (não apenas do ponto de vista intelectual, mas também existencial e pessoal). Girard permitiu, de fato, compreender a essência eventual e histórico-progressiva do cristianismo e da modernidade Normalmente todos nós, crescidos em um contexto católico, tínhamos imaginado que existisse uma antítese e uma oposição entre a essência cristã e o ser modernos) (VATTIMO; GIRARD, 2006b, p. 7).

O diálogo de Vattimo com René Girard é mediado, em particular, pela recusa da leitura vitimaria das Escrituras $^{2}$, a espoliação do aspecto vitimário das religiões [naturais]: “[...] o poder de redenção de Jesus parece consistir, para ele [Girard], em um puro e simples desmascaramento da essência da violência própria do conceito natural de sacro". (Ibidem, p. 72)

Vattimo afirma, então, que a sua leitura de Girard lhe conduziu a adotar a secularização como premissa da experiência de um cristianismo religioso e não sacrifical, embora de maneira diversa do antropólogo francês.

\footnotetext{
${ }^{2} \mathrm{Na}$ sua leitura contra a teologia vitimaria, Vattimo sustenta que "Jesus não encarna para fornecer ao Pai uma vítima adequada à sua ira, mas vem ao mundo para revelar e, portanto, também para liquidar o nexo entre a violência e o sagrado. É morto porque tal revelação é demasiado intolerável para uma humanidade radicada na tradição violenta das religiões sacrificiais". (VATTIMO, 1998, p. 28.).
}

\begin{tabular}{|l|l|l|l|l|}
\hline Qevista 2 ialectus & Ano 2 & n. 4 & Janeiro-Junho 2014 & p. 150-158 \\
\hline
\end{tabular}


Para seguir pelo caminho de um reencontro niilista do cristianismo basta ir um pouco além de Girard, admitindo que o sagrado natural é violento não só enquanto o mecanismo vitimário supõe uma divindade sedenta de vingança, mas também enquanto atribui a essa divindade todas as características de omnipotência, absolutismo, eternidade e 'transcendência' em relação ao homem que são os atributos conferidos a Deus pelas teologias naturais, e também por aquelas que se consideram preâmbulos da fé cristã. O Deus violento de Girard é, em suma, nesta perspectiva, o Deus da metafísica, aquele que a metafísica chamou também o ipsum esse subsistens, que resume em si de forma notável todas as características do ser objetivo tal como esta o pensa (VATTIMO, 1998, p. 29).

$\mathrm{Na}$ esteira da leitura não-vitimária das Escrituras, Vattimo, em sua Ontologia da debilidade, adota a kénosis de Deus ${ }^{3}$ como a condição de se pensar a experiência religiosa na época pós-metafísica que

[...] muito mais do que buscar o triunfo de uma fé sobre outra, a tarefa que todos temos pela frente é reencontrar - depois da época 'metafísica' dos absolutismos e da identidade entre verdade e autoridade - a possibilidade de uma experiência religiosa pós-moderna, na qual a relação com o individuo não seja mais poluída pelo medo, pela violência, pela superstição. (VATTIMO, 2002, p. 16).

A história da religião cristã como fio condutor da história do Ocidente como a terra do ocaso, do niilismo. A história da secularização no Ocidente (técnico-científico, democrático, pluralista...) representa a verdade do cristianismo atual. Aqui se reconhece que o Ocidente é marcado notadamente pela mensagem bíblica cristã, uma civilização que tem como sua herança a cultura cristã. A leitura da herança cristã, a interpretação de suas mensagens abandona a pretensão de uma fundamentação último-objetiva. Desse modo, a secularização é a chave de leitura do discurso sobre o fenômeno do religioso na Ontologia vattimiana, concebida como liberação da civilização [laico-moderna] de suas origens sagradas, do abandono da violência do sagrado natural com Jesus, da independência do homem do Deus absoluto, da extinção do poder temporal da igreja.

A secularização do mundo, portanto, é o resultado da intervenção do cristianismo, evitando considerar, por assim dizer, que secularização e laicismo sejam contrapostos ao cristianismo, o que de certa forma é compartilhado pelo antropólogo francês Girard.

O cristianismo nos priva daquele mecanismo que estava na base da origem social e religiosa arcaica, introduzindo-nos em uma nova fase da história do homem. Uma fase que podemos legitimamente chamar 'moderna'. Para mim, todas as conquistas da modernidade partem daquela tomada de consciência interna ao cristianismo (VATTIMO; GIRARD, 2006b, p. 6).

\footnotetext{
${ }^{3}$ Nesse sentido, Vattimo propõe que a verdade do cristianismo radica no niilismo pós-moderno, na dissolução dos metarelatos, isto é, a dissolução da concepção metafísica da verdade representa a verdade do próprio cristianismo expressa, por exemplo, na Kénosis, onde se ler "[...] a encarnação como renúncia de Deus à própria soberana transcendência”. (VATTIMO; RORTY, 2006a, p. 72.).
}

\begin{tabular}{|c|c|c|c|c|}
\hline Qevista Dialectus & Ano 2 & n. 4 & Janeiro-Junho 2014 & p. $150-158$ \\
\hline
\end{tabular}


A secularização, em suma, que se efetiva na Modernidade se vincula à dessacralização do sagrado autoritário, do absoluto e do violento da religião natural. $\mathrm{O}$ sentido 'positivo' da secularização é a ideia de que a Modernidade laica se constitui também e, sobretudo, como continuação e interpretação des-sacralizante da mensagem bíblica 4 .

\begin{abstract}
Secularização como fato positivo significa que a dissolução das estruturas sagradas da sociedade cristã, a passagem a uma ética da autonomia, à laicidade do Estado, a uma literalidade menos rígida na interpretação dos dogmas e dos preceitos, não deve ser entendida como um decréscimo ou uma despedida do cristianismo, mas como uma realização mais plena da sua verdade que é, recordemo-la, a Kénosis, o rebaixamento de Deus, o desmentir dos traços 'naturais' da divindade (VATTIMO, 1998, p. 39).
\end{abstract}

O sentido positivo da secularização continua no processo kenótico [encarnação de Deus], em direção do abandono do sagrado violento ${ }^{5}$ : “[...] a secularização, isto é, a dissolução progressiva de toda sacralidade naturalista, é a própria essência do cristianismo" (Ibidem, p. 43).

A ontologia niilista de Vattimo (re)interpreta o cristianismo, com base na sua dimensão secularizante radicada, em particular, no evento kenótico da encarnação ${ }^{6}$. A narração de Vattimo é uma história que começa apresentando a secularização como o cumprimento da mensagem central cristã, preparando-se para uma re-apropriação do cristianismo. Vattimo interpreta a natureza antimetafísica e kenótica do cristianismo como secularização, como religião do amor, da caridade, ou seja, a kénosis é a abertura ao outro, a alteridade. Não apenas isto, reconhecida a transcrição da mensagem cristã, possibilita-se inferir que, com base em tal herança, a ontologia niilista vattimiana, por um lado, presume a 'circularidade' entre herança cristã, ontologia [debole] e ética; e, por outro lado, inspira a sua (re)leitura sobre o fenômeno da religiosidade na época pósmetafísica como um dos horizontes fundamentais de sua filosofia. Por fim, mas ainda sem assumir um caráter definitivamente conclusivo, o re-encontro com o cristianismo, então, na época do fim da Metafísica, é motivado por razões estritamente éticas que

\footnotetext{
${ }^{4}$ Vattimo, na obra Depois da Cristandade [2004, p. 60], expõe que "o sentido em que emprego o termo secularização é exatamente este: uma aplicação interpretativa da mensagem bíblica que a desloca para um plano que não é estritamente sacramental, sagrado, eclesiástico".

${ }^{5}$ Vattimo sustenta que a espiritualização de Deus vai em direção da "[...] liquidação do sacro, também no sentido da diminuição da violência, do sofrimento, dos problemas insolúveis que evocam, em seguida, a necessidade do sacro como necessidade de soluções absolutas" (VATTIMO, 1990, p. 73.).

${ }^{6}$ Rorty sustenta em relação a Vattimo que "sua estratégia é tratar a encarnação como sacrifício de todo poder e autoridade de Deus, tão bem quanto todas as outras passagens. A encarnação é um ato de kénosis, o ato em que Deus trocou tudo com os seres. Isso permite a Vattimo fazer sua mais impressionante e importante afirmação: que a secularização [...] é o traço constitutivo da experiência religiosa autêntica". (RORTY: VATTIMO, 2006a, p. 54.).
}

\begin{tabular}{|l|l|l|l|l|}
\hline Qevista Dialectus & Ano 2 & n. 4 & Janeiro-Junho 2014 & p. 150-158 \\
\hline
\end{tabular}


teórico-filosófico-teológicas, o que ainda demanda uma investigação mais aprofundada.

\section{Referências Bibliográficas}

ANTISERI, D. Le Ragioni del Pensiero Debole. Domanda a Gianni Vattimo. Roma: Burla, 1995.

GIORGIO, G. Nichilismo ermeneutico e política. A Parte Rei. Revista de Filosofia. Madrid, Noviembre, 2007.

Il Pensiero di Gianni Vattimo - l'emancipazione dalla metafisica tra dialettica ed ermeneutica. Milano: FrancoAngeli, 2006.

MONACO, David. Gianni Vattimo - Ontologia ermeneutica, cristianesimo e postmodernità. Pisa: Edizioni ETS, 2006.

PECORARO, R. Niilismo e (pós)modernidade. São Paulo: Loyola, 2005.

RORTY, Richard. Anticlericalismo e ateísmo. IN: VATTIMO, Gianni; RORTY, Richard. Futuro da Religião. 2006a.

VATTIMO, G. Oltre l'Interpretazione. Il significato dell'ermeneutica per la filosofia (Lezioni italiane). Roma-Bari: Laterza, 1994.

. Etica dell'Interpretazione. Torino: Rosenberg \& Sellier, 1989.

2006c.

Non essere Dio - un'autobiografia a quattro mani. Torino: Aliberti editore,

Depois da Cristandade. Trad. Cynthia Marques. Rio de Janeiro: Record, 2004.

Filosofia al presente. Conversazioni con F. Barone, R. Bodei, I. Mancini, V. Mathieu, M. Perniola, P.A. Rovatti, E. Severino, C. Sini. Milano: Garzanti, 1990.

. Verdadeiro e falso. Universalismo cristão. Rio de Janeiro: EDUCAR, Academia de Latinidade, 2002.

VATTIMO, Gianni; GIRARD, Renê. Veritá o fede debole? Dialogo su cristianesimo e relativismo. Pisa: Transeuropa, $2006 \mathrm{~b}$.

Acreditar em Acreditar. Trad. Elsa Castro Neves. Lisboa: Relógio D’Água editores, 1998.

; ANTISERI, Dário. Ragione filosofica e fede religiosa nell'era postmoderna. Soveria Mannelli: Rubbettino Editore, 2008.

; DERRIDA, Jacques. A Religião: o seminário de Capri. São Paulo: Estação Liberdade, 2000.

\begin{tabular}{|l|l|l|l|l|}
\hline Qevista Dialectus & Ano 2 & n. 4 & Janeiro-Junho 2014 & p. 150-158 \\
\hline
\end{tabular}


; D'ARCAIS, Paolo Flores; ONFRAY, Michel. Atei o credenti? Filosofia, politica, etica, scienza. Roma: Fazi editore, 2007.

; SEQUERI, Pierangelo; RUGGERI, Giovanni. Interrogazioni sul cristianesimo. Cosa possiamo ancora attenderci dal Vangelo? Roma: Edizioni Lavoro, 2000.

ZABALA, Santiago. La religión de Gianni Vattimo. El cristianismo después de la muerte de Dios IN: Claves de razón practica, no. 132, Madrid: marzo de 2003. 